MARINE MAMMAL SCIENCE, 12(4):602-606 (October 1996)

(C) 1996 by the Society for Marine Mammalogy

\title{
APPROACH BY GREAT WHITE SHARK ELICITS FLIGHT RESPONSE IN BOTTLENOSE DOLPHINS
}

Sharks have been identified as important predators on bottlenose dolphins in several locations, but no actual attacks have been observed and reports of interactions between bottlenose dolphins and sharks are few. Here we report a strong avoidance reaction by a group of nine bottlenose dolphins (Tursiops sp.) to an approach by a $2.5-3.0-\mathrm{m}$ great white shark (Carcharodon carcharias) in Shark Bay, Western Australia. Bottlenose dolphins in Shark Bay are among the smallest known; adult females measured have ranged from 186-207 cm and one adult male was measured at around $210 \mathrm{~cm}$ (unpublished data, Smolker et al. 1992). Thus, at $2.5-3.0 \mathrm{~m}$, the shark was longer than the dolphins it encountered.

Evidence for the importance of shark predation on bottlenose dolphins 
comes mostly from scars on living animals and shark stomach contents. In Moreton Bay, Queensland, shark attack scars were found on $36 \%$ of 334 individually identified bottlenose dolphins (Corkeron et al. 1987). Shark scars were found on over $22 \%$ of individuals closely examined during temporary captures in Sarasota Bay, Florida (Wells 1991). Off the Natal coast of South Africa shark scars were found on $15(10 \%)$ of 145 individuals caught incidentally in nets set to protect bathers from sharks, and another 13 dolphins had scars that may have been from sharks (for a possible total of 19\%) (Cockcroft et al. 1989). Based on stomach contents of shatks caught in the same nets, four species were identified as the most common prcdators on bottlenose dolphins in Natal: the bull, Carcharbinus leucus; dusky, Carcharbinus obscurus; tiger, Galeocerdo cuvieri; and great white shark. These same four species have been implicated in attacks on dolphins elsewhere (McBride and Hebb 1948, Wood et al. 1970, Corkeron et al. 1987).

Although direct observations of shark attacks on wild dolphins are lacking, a five-month-old calf in Sarasota Bay, Florida, clearly died from wounds received from a shark (Wells 1991). In Shark Bay, where several dolphins are provisioned with fish in the 'Monkey Mia' shallows (Connor and Smolker 1985), tourists observed an approximately 2-m tiger shark kill a four-monthold infant ( $\mathrm{J}$. Mann, personal communication).

The interaction we observed (and videotaped) occurred on 18 July 1994 in Red Cliff Bay on the east side of Peron peninsula in Shark Bay. At approximately 1615 we observed, photographed, and videotaped a $2.5-3.0-\mathrm{m}$ great white shark traveling slowly (about $2 \mathrm{~km} / \mathrm{h}$ ) south in glassy calm conditions, with its dorsal fin protruding above the surface. About 10 min after we encountered the shark, it turned in a more westerly direction toward a group of 8-9 dolphins, all females and calves, floating at the surface about $200 \mathrm{~m}$ away. We consider dolphins floating at the surface in a tight group (less than one body length apart) to be resting (Connor and Smolker 1990).

Videotape confirmed the presence of eight dolphins in the group prior to the shark encounter, but we identified nine individuals following the interaction and consider it likely that all nine were present from the beginning. In the group of nine were three mothers with dependent calves (two 3.5-4.0yr-old calves and one 4.5-5.0-yr-old), including a primiparous female who was eight months pregnant, a pregnant parous female, and a parous female that did not appear pregnant and did not give birth during the following year. The remaining three females were nulliparous, including a 14.5 -yr-old that was eight months pregnant, and two whose exact ages are unknown that were first observed as dependent calves in 1984 and 1985, respectively. These two females did not appear pregnant or produce a calf during the following year.

The shark did not deviate from its course or speed until it swam into the dolphin group, which continued to float at the surface until the shark approached to within 2-3 $\mathrm{m}$, at 1631 , when the entire group of dolphins suddenly submerged. Approximately $28 \mathrm{sec}$ after submerging (timed on videotape), the dolphins emerged, leaping to the northeast and northwest. Initial leaps were higher and longer than those that followed. Within a minute the 
leaping dolphins had coalesced into two groups, one group of four individuals leaping in a northwesterly direction and one group of five dolphins leaping in a northeasterly, then northerly direction. The group traveling to the northwest ceased leaping eight minutes after they began, while the other group continued leaping another two minutes (until 1641:50) before slowing down somewhat, just over 10 min after the shark swam into the group. At 1.651: 40 we noted that the two groups were paralleling each other $200 \mathrm{~m}$ apart, but by 1652:00 they were traveling on an intersecting course and rejoined at 1658:00, $27 \mathrm{~min}$ after the shark encounter. When the groups rejoined we noted a few surfacings that were rapid and the dolphins briefly formed a very tight group, with some individuals less than $0.3 \mathrm{~m}$ apart, indicating possible socializing. For the last $10 \mathrm{~min}$ that we observed the group, they traveled in one group, then later two subgroups, performing dives in which they lifted their flukes or humped their peduncles out of the water; a class of behavior that, in addition to floating at the surface, we consider resting. None of the dolphins in the group exhibited any evidence of having been bitten by the shark.

We did not record the entire distance the dolphins covered while leaping, but recorded the distance traveled between 1639:42 and 1644:10 at $1.3 \mathrm{~km}$, for an estimated speed of $17 \mathrm{~km} / \mathrm{h}$ during this phase, which included two minutes after they had ceased leaping but were still traveling fast. On uumerous other occasions we have recorded the speed of dolphins leaping during long social chases or leaping toward a feeding group at $16-19 \mathrm{~km} / \mathrm{h}$. 'Normal' traveling speeds for dolphins in this population range from $1.5-4 \mathrm{~km} / \mathrm{h}$ (unpublished data). At $16-19 \mathrm{~km} / \mathrm{h}$, the group leaping to the northwest for eight minutes would have covered $2.1-2.5 \mathrm{~km}$, and the group leaping north for 10 min would have traveled $2.7-3.2 \mathrm{~km}$, yielding a reasonable estimate of $3 \mathrm{~km}$ for the distance traveled by this group while leaping.

A possibly similar dolphin-shark interaction occurred on 15 August 1995, just as two groups traveling slowly joined to form a large mixed-sex group of 15 individuals, including two calves. Almost immediately, they turned northwest and began traveling rapidly but not leaping (estimated speed, 8-10 $\mathrm{km} / \mathrm{h}$ ). At about that same time a mother/calf pair that had been foraging 30 $\mathrm{m}$ away joined the fast-traveling group, bringing the group size to 17 (14 adults, 3 calves). Just as the group began moving away rapidly, we observed the fin-tip of a shark of unknown species or size for a few seconds before it disappeared under the water, moving away from the direction the dolphins were traveling. From previous observations in Shark Bay, we know that similarly small fin-tips protruding above the surface may belong to sharks $3 \mathrm{~m}$ or more in length. After $8-9$ min of fast traveling the dolphins slowed down, and four minutes after they slowed, the mother/calf that had been foraging left the group. The others remained together for the final one hour of observation. We estimate that the dolphins traveled $1.0-1.5 \mathrm{~km}$ before they slowed down. This case suggests that flight reactions to the presence of large predatory sharks may not be uncommon in Shark Bay but difficult to document if the shark is nor visible at the surface. 
Previous reports indicate that the response of bottlenose dolphins to the presence of sharks varies with species and circumstance. Captive dolphins trained to repel sandbar (Carcharbinus milberti), lemon (Negaprion brevirostris), and nurse sharks (Ginglyostoma cirratum) became agitated and refused to respond to command when bull sharks were introduced (Irvine et al. 1973). McBride and Hebb (1948) noted that captive bottlenose dolphins exhibited a stronger negative reaction to tiger sharks than other species, avoiding an adult tiger and killing two smaller ones. In the wild, reported reactions to the presence of sharks vary from herding the shark, to avoidance, to no apparent response at all (Wood et al. 1970, Leatherwood 1977). In South African coastal waters Taylor and Saayman (1973) observed bottlenose dolphins avoid a large hammerhead by splitting into two groups, which increased speed and swam past the shark on either side before rejoining. Another group of bottlenose dolphins dove to more than $10 \mathrm{~m}$ when they crossed paths with a great white shark (Taylor and Saayman 1973). None of the reported observations suggest the kind of strong flight response we observed in Shark Bay.

\section{ACKNOWLEDGMENTS}

We thank Colin Simfendorpher for identifying the shark.

\section{Literature Cited}

Cockcroft, V. G., G. Curfr and G. J. B. Ross. 1989. Shark predation on Indian Ocean bottlenose dolphins Tursiops trincatus off Natal, South Africa. South African Journal of Zoology 24:305-310.

Connor, R. C., AND R. A. Smolker. 1985. Habituated dolphins (Tursiops sp.) in Western Australia. Journal of Mammalogy 66:398-400.

ConNor, R. C., AND R. A. SMON.kFr. 1990. Quantitative description of a rare behavioral event: A bottlenose dolphin's behavior toward her deceased offspring. Pages 355-360 in S. Leatherwood and R. R. Reeves, eds. The bottlenose dolphin. Academic Press, San Diego, CA.

Corkeron, P. J., R. J. Morris and M. M. Bryden. 1987. Interactions between bottlenose dolphins and sharks in Moreton Bay, Queensland. Aquatic Mammals 13: 109-113.

Irvine, B., R. S. Welis and P. W. Gilbert. 1973. Conditioning an Atlantic bottlenosed dolphin, Tursiops truncatus, to repel various species of sharks. Journal of Mammalogy 54: 503-505.

LEATHER wOOD, S. 1977. Some preliminary impressions on the numbers and social behavior of free-swimming bottlenose dolphin calves (Tursiops truncatus) in the northern Gulf of Mexico. Pages 143-167 in S. H. Ridgway and K. Benirschke, eds. Breeding dolphins; Present status, suggestions for the future. Report \#MMC76/77, Marine Mammal Commission, Washington, DC. 308 pp.

McBride, A. F., AND D. O. Hebs. 1948. Behavior of the captive bottlenose dolphin Tursiops truncatus. Journal of Comparative Physiology and Psychology 41:111123.

Smolker, R. A., A. F. Richards, R. C. Connor and J. W. Pepper. 1992. Sex differences in patterns of association among Indian Ocean bottlenose dolphins. Behaviour 123:38-69.

TAYLER, C. K., AND G. S. SAAYMan. 1973. The social organization and behaviour of 
bottlenose dolphins (Tursiops aduncus) and baboons (Papio ursinus): Some comparisons and assessments. Annals of the Cape Provencial Museums (Natural History). $9(2): 11-49$

WeLLs, R. S. 1991. Bringing up baby. Natural History. August:56-62.

Wood, F. G. JR., D. K. Caldwell and M. C. Caldwell. 1970. Behavioral interactions between porpoises and sharks. Investigations on Cetacea 2:264-277.

Richard C. Connor, Museum of Zoology, University of Michigan, Ann Arbor, Michigan 48109, U.S.A.; Michael R. Heithaus, Biology Department, Oberlin College, Oberlin, Ohio 44074, U.S.A. Received 18 October 1995. Accepted 29 February 1996. 